\title{
On being heckled at a National Health Technology Conference: Patient participation and democratic discourse
}

\section{SHARON BATT}

\section{Abstract}

This article uses my experience of being heckled by patient advocates at a health technology conference in Canada as a springboard for discussing the politics of health technology assessment (HTA). While HTA is widely understood and practised as a scientific endeavour grounded in rigorous quantitative research methods, the socio-political aspects of HTA cannot be separated from the scientific. Integrating the social, political, and ethical dimensions of HTA into the practice of assessment means understanding how a technology will shift power relationships among actors, alter resource flows, and affect how knowledge is produced and circulated. I suggest these factors contributed to the hostile reception I received when I attempted to present a paper about the biased selection of patient advocates involved in Canada's main HTA agency. As India embarks on the challenge of establishing its own agency to support healthcare decisionmaking, and as patient advocacy groups rise in India with the support of the pharmaceutical industry, I offer this account as a cautionary tale to those shaping India's new agency.

\section{An unexpected attack}

"You are a disgrace," "You lied," "You have set patient engagement at CADTH back thirty years." These insults were among those hurled at me as I approached the meeting room at a conference centre in April 2018, where I was about to present a paper about patient engagement in drug policy in Canada. The setting was the national symposium of the health technology assessment (HTA) agency, the Canadian Agency for Drugs and Technologies in Health (CADTH). The hecklers were three very angry women, two of whom I recognised as prominent patient activists. Taken aback, I said, "I'm sorry you feel that way," which did nothing to soften their hostile looks. As I headed to the speakers' table at the front of the room, a woman in the audience gently touched my arm. "Are you ok?" she asked. I wasn't sure that I was.

\footnotetext{
Author: Sharon Batt (Sharon.Batt@Dal.Ca), Adjunct Professor, Department of Bioethics, Dalhousie University, Halifax, B3H 4R2 CANADA.

To cite: Batt S. On being heckled at a National Health Technology Conference: Patient participation and democratic discourse. Indian J Med Ethics. 2020 Apr-Jun;5(2) NS: 128-33. DOI:10.20529/JME.2020.027.

Published online on March 11,2020.

Manuscript Editor:Veena Johari

Peer Reviewers:Vivek Divan and an anonymous reviewer.

OIndian Journal of Medical Ethics 2020
}

At the speakers' table, I looked up to see the three women now sitting immediately in front of me. "You shouldn't be allowed to speak," they continued, "You're just here to promote your book!" The latter reference was to Health Advocacy Inc., which documents how the pharmaceutical industry became the main source of funds for patient advocacy organisations in Canada, splitting the organised patient community. One faction believes independence from industry is a prerequisite for acting in patients' interests, the other contends that industry money does not influence their advocacy $(1,2)$. I saw no shame in discussing my book at a conference where participants could question and debate my claims.

"I think we need a code of conduct," said the moderator, addressing the hostile trio.

"We need a code of conduct for speakers," one shot back.

The moderator then suggested that I might prefer not to present my paper. I hesitated: I had submitted an abstract for consideration, it had been accepted, and I had spent many hours preparing the talk, which some of the people now filling the room presumably wanted to hear. Yet the hecklers obviously intended to disrupt my presentation and apparently felt entitled do so. Reluctantly, I agreed not to present, but to have my slides posted on the conference website.

My aborted talk, titled, "Patient voices: whose stories are missing, why, and so what?"(3) arose from my observation at two previous CADTH symposia that the preponderance of patients attending want to have new drugs recommended for placement on provincial formularies, in order to expand treatment choices. I had rarely, if ever, heard patients speak at CADTH about drug safety and efficacy, about the impact of rising drug prices on the viability of the public healthcare system, or about systemic biases in clinical trials. And yet, I had been involved for more than two decades with patient and health activist organisations that prioritised these issues. I attributed the homogeneity of patients' voices at CADTH to the substantial funding the pharmaceutical industry provides to patient organisations whose views align with its own, while groups willing to critique the industry struggle to survive.

Yielding to the hecklers' pressure was distasteful; nonetheless, the "heckling activists" story sent shock waves through Canada's drug policy community and caused no small embarrassment within CADTH itself. CADTH's Manager for Patient Engagement soon sought me out to apologise and to assert that CADTH's meetings were venues for the discussion 
of diverse points of view. She insisted on accompanying me to sessions for the rest of the conference, to ensure my safety. The next day, she and the conference organiser apologised again by e-mail.

\section{Patient engagement and health technology assessment}

I was not so disingenuous as to think my paper would be enthusiastically received. The previous day, I had participated on a panel that discussed whether "patient engagement" had become just another buzzword (4); patient advocates and industry representatives in the audience challenged the panellists individually and as a group. Furthermore, naming CADTH's systemic failure to incorporate the full range of patient perspectives implicitly cast doubt on the legitimacy of the patients who dominated CADTH's meetings, its advisory bodies, and its drug evaluations. Nonetheless, I was surprised to see such aggressive behaviour at a professional conference and to have it tolerated. Why were the hecklers not told to act with civility or leave the meeting room? I return to these concerns later, but first I examine the rationale for including patients in agencies like CADTH in the first place.

Established in 1989, CADTH bills itself as an independent, notfor-profit, non-governmental agency. Like the National Institute for Health and Care Excellence (NICE) in the United Kingdom and some 50 other agencies globally, the agency took its inspiration from the US Office of Technology Assessment (OTA) which was founded in 1972 and disbanded in 1995 (5). A recent bipartisan Act seeks to revive the OTA (6).

Technology assessments, although they rely on scientific methodologies, can threaten vested interests and, thus, have a political dimension, which is not always acknowledged. HTA agencies critically analyse the evidence from scientific research on the risks and benefits of drugs and medical devices and assess whether they are cost-effective. Based on this evaluation, CADTH's mandate includes advising Canada's provincial and territorial governments ${ }^{1}$ on whether to include a new drug or device on their public insurance formularies (lists of drugs covered under an insurance plan). Although regional governments are not obliged to follow CADTH's recommendations, the agency strongly influences which drugs will be available under publicly funded plans. These decisions can directly affect patients' lives. They also affect drug companies' bottom lines.

The drive to involve patients in HTA is widespread and based on considerations of both knowledge and ethics. As end-users of a technology, patients have experiential knowledge that complements research-based understanding of a technology's "relevance to healthcare goals and needs." (7: p 7) The patient's status as the end-user further supports inclusion, based on "fairness and legitimacy through democratic participation." (7: $p$ 17) These strong justifications for including patients in HTA beg the question," which patient group should be represented"? (7: p 17) My paper argued that CADTH had fallen short on this critical question, distorting in turn the issues of knowledge and fairness.
CADTH has made efforts to include patients in many aspects of its work since 2010 (8), such as hiring a Manager for Patient Engagement, inviting patient organisations to send online comments on drugs and devices under review, and including patients on its review committees. Furthermore, CADTH includes patients at its annual symposium, and meets the criteria set out by the international organisation Patients Included, which rates medical meetings on whether they have sufficient involvement from the patient community. ${ }^{2}$ Patients with endorsement from a patient organisation can apply for funds to cover their symposium expenses. For three consecutive years, CADTH awarded me travel support to represent Breast Cancer Action Quebec (BCAQ), a group I cofounded following a diagnosis of breast cancer.

\section{Patient engagement and pharma's shadow presence}

Including the perspective of patients and public health advocates independent of the pharmaceutical industry is crucial because these organisations often oppose the very positions that their pharma-funded counterparts adopt, including access campaigns for new, expensive, problematic drugs. In both Canada and the United States, the latter include Avastin for breast cancer (ineffective, with potentially lethal adverse effects including heart attacks and bleeding) $(9,10)$, Erythropoietin, promoted to alleviate anaemia or fatigue in cancer patients, but found to promote tumour growth and fatal thrombotic events $(11,1)$, and opioids like OxyContin for non-cancer pain, a root cause of the epidemic now costing thousands of lives annually in Canada, and tens of thousands in the United States $(12,13)$.

Two recent analyses support my impression of extensive pharmaceutical industry funding among the patient organisations engaged with CADTH's drug evaluation process. Health journalist Kelly Grant found that, of more than 400 written patient organisation submissions, the organisation sending the submission had a financial conflict of interest with the manufacturer of the drug under review in 78 per cent of comments on drugs in general, and 86 per cent of comments on cancer drugs (14). Physician and drug policy analyst Joel Lexchin examined all 372 patient group submissions over a six-year period and found that 87.1 per cent declared a conflict, with a median of seven conflicts per submission (15).

Findings from studies in the United Kingdom and Australia are strikingly similar. Among patient organisations participating in assessments at NICE, 72 per cent had accepted funds from the manufacturers of a technology or a competitor product in the same or previous year that they contributed to the appraisal of that technology (16). Decision-makers at NICE were aware of only 21 per cent of the conflicts. In Australia, 34 pharmaceutical companies collectively spent AU $\$ 34,507,810$ to sponsor 230 organisations participating on that country's Pharmaceutical Benefits Advisory Committee. Among the most heavily funded were organisations representing conditions for which companies had treatments under review for public reimbursement (17). 
By contrast, my sponsoring organisation has a written policy on corporate donations that explicitly precludes accepting funds from the pharmaceutical industry (18). BCAQ is among a small but increasingly vocal group of patients' organisations in Canada that openly challenge exorbitant drug prices and questionable claims of the pharmaceutical industry. Likeminded organisations include Faces of Pharmacare, the CML Society of Canada (representing Chronic Myelogenous Leukaemia patients), the Liv-A-Little Foundation (representing patients with Cystinosis and their family caregivers) and the coalition Independent Voices for Safe and Effective Drugs, to which I belong.

The groups that receive industry funds articulate a perspective about new drugs and devices that aligns closely with that of the pharmaceutical industry. Joel Lexchin found that 90.2 per cent of the submissions of groups that participated in CADTH's drug assessment process were positive, nine per cent were neutral and only 0.7 per cent were negative. When CADTH's reviewers recommended against funding a new cancer drug, the patient groups usually disagreed (17 of 19 cases), but when reviewers recommended in favour of a drug's approval, the patient groups almost always agreed (48 of 51 cases) (15). Yet an "overwhelming majority" of patient group leaders that Kelly Grant interviewed for her newspaper investigation said that drug makers that fund their groups "have no say whatsoever in their policy positions." (14)

Group leaders attribute the similarity of their views and the industry's to "a 'natural alignment' between the patient groups fighting for access to new treatments and the companies that make them." (14) Company representatives, similarly, dismiss price concerns because when provincial governments agree to pay for a high-priced drug, no family is left out of pocket. Erin Little of the Liv-A-Little Foundation disagrees: "As a taxpayer I do pay it.We should all collectively care," she says (14).

\section{Pharma's web of influence in health technology assessment}

Given that HTA is meant to reduce the use of unproven clinical procedures on patients, which can be both useless and harmful, one might expect the HTA culture to be wary of industry influence. And yet, internationally, HTA agencies embrace a model of partnership with industry that is endemic in medicine, and not only with respect to funding patient organisations $(19,20,21)$. In 2018, David Banta, a physician and international HTA pioneer, wrote in a personal reflection on his 40 plus years in the field:"my greatest concern today is the role of industry in HTA. ... how can we refer to industry as partners when our first concern is the public health? The commercial health care industry is mostly concerned with creating returns for their shareholders." (22: p 133)

CADTH is largely government-funded but receives some funding from industry. In 2018, two external evaluators questioned the degree and type of involvement CADTH should have with the private sector. Based on stakeholder interviews, they flagged CADTH's engagement with industry in three contexts, including patient representatives whose work is funded by industry (23: p 85). Like Banta, the report's authors stressed the need "to ensure that the organization continues to be seen as acting squarely in pursuit of the public interest." (23: p 85)

These "public-private partnerships" between patient organisations and Big Pharma are part of a web of influence that includes the medical research community (24), medical education (25), and regulatory and quasi-regulatory agencies like CADTH (26). Collectively they reinforce the industry's interests throughout the medical system. Beginning in the late 1990s, for example, Purdue Pharma Canada formed partnerships with multiple policy actors in Canada to encourage the use of OxyContin, its new drug to control noncancer pain, which the company falsely claimed was nonaddictive. The company funded three patient organisations for chronic pain sufferers (13), placed advertisements in medical journals, provided medical school students with a free textbook copyrighted by Purdue, and paid about 100 physicians annually to give lunchtime talks to doctors about an "epidemic of untreated pain." (27) Voting members on an expert committee named to develop opioid prescribing guidelines for pain control included one physician who received compensation from Purdue and a broader expert advisory committee on which six of 13 members had ties to opioid manufacturers (28).

Importantly, however, within patient and health organisations, as in each of these other health sectors, a contingent of organisations resisted the privatisation wave as fundamentally at odds with the public interest. These included DES Action Canada, Breast Cancer Action Quebec, Women and Health Protection, Pharmawatch Canada, the Canadian Women's Health Network, and the Society for Diabetic Rights.

\section{The roots of a heckling culture}

In the months since being heckled, I've puzzled over what happened and why. At the conference itself, sympathetic people approached me to say they thought I had "struck a nerve." Indeed, two prominent patient advocates who are involved with CADTH, Martine Elias and Durhane WongRieger, say they are "weary" of being criticised for accepting pharma funding (14). Elias calls such critiques "an excuse to ignore [their] input on health policy issues" (14); Wong-Rieger describes them as a way "to contain or minimize patient involvement." (29: p 377) In fact the point is to expand inclusion to patients who see industry as a barrier to obtaining the best available evidence on health technologies. Many of us came to that understanding through our experience as patients or caregivers.

Patients can and do have different experiences with drugs. These, and different personal values, lead to differences of opinion - why not discuss them? Why heckle? Michael White, political commentator at The Guardian, argues that heckling has a place in political discourse as a form of intellectual engagement but he distinguishes "proper heckling," 
characterised by wit and impeccable timing, from the blunt instruments of anger and abuse (30). I put my experience in the latter category: the attacks were pre-emptive and showed neither wit nor true argumentation. In this guise, heckling expresses an authoritarian mind set that threatens both democratic pluralism and the questioning essential to scientific inquiry.

If we idealise research forums as spaces of rational discourse, we can easily overlook their political dimensions. Two scholars of HTA, Pascale Lehoux and Stuart Blume, argue that, while the dominant approach to HTA tends to focus narrowly on technical and clinical evidence, HTA is political, and these dimensions need to be given more attention (31). If we consider HTA as political, the bullying I experienced is less startling. In fact, egregious examples of disrespect aimed at those who contest the safety or efficacy of profitable "advances" are not uncommon in the literature on health technologies.

Peter Gøtzsche's expulsion from the Cochrane Collaboration's governing board in September 2018 stands out as a highprofile recent case and has been discussed in many venues, including this one (32). But intolerance of critique has deep roots in HTA. In a book-length account of mammography screening debates (33), Renée Pellerin recounts surgeon Charles Wright's experience in the late 1980s as an invited speaker at a conference on mammography at Johns Hopkins University. Wright described research he had published (34) in which he concluded that harms of breast screening far outweighed the benefits and that only women at high risk of breast cancer should be screened. After his talk, Wright recalls, "a very angry-looking elderly radiologist came up and sort of punched me in the chest with his finger and said, 'You don't understand boy; you've got your hand in our pockets." (33: p 71) In another case, David Banta and Stephen Thacker describe the attacks on their objectivity and integrity when their research led them to question the efficacy and safety of electronic fetal monitoring (35: pp 764-6). Two doctors, who wrote in the BMJ and the San Francisco Chronicle that the evidence does not support routine screening for prostate cancer, became the target of a prostate cancer advocacy group, Us Too! International, which received 95 per cent of its funding from the pharmaceutical industry (36). And when the BMJ published the 25-year update of the Canadian Breast Screening Study in 2014, which concluded that mammography screening does more harm than good, the study's deputy director, Cornelia Baines, received an email from a radiologist saying he "hoped she would be haunted by the faces of all the women who would die because of her." (33: p 14)

Such tactics should remind us that science and politics are inseparable and socio-political analysis needs to be part of HTA. Lehoux and Blume identify four sets of issues to include in an expanded research model: the potential actors involved, the flow of material and human resources that the technology implies, the production and circulation of knowledge, and the technology's effect on power relations (31:pp 1092-3).
They stress that "Organized groups may struggle to protect their assets and attempt to exercise power over the projects of others." (31:p 1091) We should therefore not be puzzled if obstetricians protest evidence that questions electronic foetal monitoring or if radiologists attack analysts who conclude mammography screening does more harm than good.

\section{The politics of patient group advocacy}

Nor should we be surprised when patient advocates who work in partnership with the pharmaceutical industry harass an advocate who questions their claims about the value of new drug treatments to patients. Lehoux and Blume write that controversy brings out a health technology's social and political dimensions:

Tensions are revealed when competing definitions of a technology's value and relevance are publicly articulated. Tensions also emerge when groups of actors feel threatened or perceive themselves at risk of losing power and authority, particularly when such groups possess the resources or "cultural capital" to express their discontent (mobilizing the media, voicing their concerns publicly). (31:p 1091)

The two hecklers that I recognised certainly possessed resources and cultural capital. They have led national organisations and projects that declare receiving funds from pharmaceutical companies while engaging in activities that could shape the public discourse on drug policy. In other words, they qualify as "Patient Opinion Leaders" (37, 1: pp 2757) - influential patient counterparts to the industry-funded physicians known as "Key Opinion Leaders" $(38,39)$.

\section{Conclusion}

If patient involvement at CADTH and other HTA agencies is to mean anything at all, differences among patient representatives on drug policy need to be aired. The meetings of HTA organisations should be venues for informed and substantive debates on conflicting evidence claims, including evidence arising from patients' varied lived experiences. This means discussing patients' perspectives on the significant harms that drugs and devices can cause $(40,41)$. It means listening to patients who ask why the drugs they take "are so ridiculously expensive, how can I possibly be using something that costs as much as my house every year?" (42).

I believe these are precisely the discussions that the advocates who heckled me want to prevent. Their actions endanger scientific inquiry and discredit patient engagement in HTA.

\section{Postscript: Changes at CADTH}

In January 2019, CADTH introduced a Code of Conduct for events like the annual symposium (43). The Code states that anyone registering for a CADTH event must "agree that harassment or disrespectful conduct do not belong at any CADTH event." The Code includes as examples, "behaviour that demeans or embarrasses a person," and "sustained disruption of a speaker"; it asserts that CADTH will take complaints of 
harassment seriously, and may contact local law enforcement or exclude the offender from attending future CADTH events.

Also, in the year following my aborted talk, CADTH disbanded its Patient Community Liaison Forum, an advisory group active from 2013 to 2018 (44) which comprised representatives from four national patient coalitions, three of which were industryfunded. The agency formed a new lay consultation group, the Patient and Community Advisory Committee, most of whose 12 members declared no industry ties (45). Both these changes have the potential to make CADTH a venue at which the full range of patient experiences and values can be discussed.

\section{Acknowledgements}

I thank the IJME's two reviewers for helpful comments on an earlier version of this paper. I am also indebted to Amar Jesani for encouraging me to write about this experience for the IJME, to IJME editors, and to colleagues Jennifer Beeman, Adriane FughBerman, Janice Graham, Patricia Kearns, Joel Lexchin, Nav Persaud and Mark Wilson for their support and belief that the incident should be aired.

\section{Statement of conflicts of interest}

The author has no financial conflicts of interest or funding support to declare.

\section{Notes}

1. Canada is divided into 10 provinces and three Northern territories with healthcare delivery designated as a provincial/territorial responsibility. Within certain parameters set by the federal government, each province or territory decides how health funds are spent, including whether or not to cover the costs of specific drugs and medical devices. Quebec has its own HTA agency, INNESS, independent of CADTH.

2. The Patients Included website is available from:https://patientsincluded. org/conferences/

\section{References}

1. Batt S. Health Advocacy Inc: How pharmaceutical funding changed the breast cancer movement. Vancouver: UBC Press; 2017

2. King NMP. On patients, prescriptions and profits [Book review of Health Advocacy Inc] Indian J Med Ethics. 2018 Jan 8 [cited 2020 Feb 26]. doi: 10.20529/ijme.2018.009 Available from: https://ijme.in/articles/onpatients-prescriptions-and-profits/?galley $=\mathrm{html}$

3. Batt S. Patient voices: whose voices are missing? Why? And so what? [conference presentation] CADTH Symposium, 2018 Apr 17 [cited 2020 Feb 23]. Abstract and slides available from: https://cadth.ca/ symposium2018/patients-experience ; https://cadth.ca/sites/default/ files/symp-2018/presentations/april17-2018/Concurrent-Session-D6Patient-Voices.pdf

4. Batt S, MacKay K, McLeod C, McNamara K, Sue-Wah-Sing D, Swan B, Vethanayagam $D$. Patients, patient groups and patient engagement: blockbuster or boondoggle? [Conference panel]. CADTH Symposium, 2018 Apr 16 [cited 2020 Feb 23]. Abstract and slides available from: https://cadth.ca/symposium2018/patients-patient-groups-andpatient-engagement-blockbuster-or-boondoggle.

5. Banta D. What is technology assessment? Int J Technol Assess Health Care. 2009 Jul 25; Suppl 1:7-9. doi: 10.1017/S0266462309090333

6. IPWatchdog. Bipartisan effort to resurrect Office of Technology Assessment introduced. 2019 Sept 20 [cited 2020 Feb 24]. Available from: ipwatchdog.com/2019/09/20/bipartisan-effort-resurrect-officetechnology-assessment-introduced/id=113584/

7. Sandman L, Bond K, Hofmann B. Exploring ethical rationales. In: Facey KM, Hanson HP, Single ANV, editors. Patient involvement in health technology assessment. Singapore: Springer Nature; 2017. pp. 17-29.

8. Weeks L, MacPhail E, Berglas S, Mujoomdar M. Country approaches:
Canada.In:Facey KM, Hanson HP, Single ANV, editors. Patient involvement in health technology assessment. Singapore: Springer Nature; 2017. pp. 247-63.

9. Pollack A. Breast cancer patients plead for Avastin approval. New York Times 2011 Jun 28 [cited 2020 Feb 24]. Available from: https://www. nytimes.com/2011/06/29/business/29drug.html

10. Canadian Press. Avastin approval for breast cancer pulled. CBC News. 2011 Nov 28. [cited 2020 Feb 24]. Available from: https://www.cbc.ca/ news/health/avastin-approval-for-breast-cancer-pulled-1.1076652

11. Brawley OW, Goldberg P. How we do harm: A doctor breaks rank about being sick in America. New York: St. Martin's Press; 2012. pp. 77-8, p. 96.

12. McCaskill C. Fueling an epidemic: Exposing the financial ties between opioid manufacturers and third party advocacy groups. Washington (DC): US Senate Homeland Security \& Governmental Affairs Committee, Ranking Member's Office. Report Two; 2018 Feb 1[cited 2020 Feb 24]. Available from: https://www.hsgac.senate.gov/imo/media/ doc/REPORT-Fueling\%20an\%20Epidemic-Exposing $\% 20$ the $\% 20$ Financial\%20Ties\%20Between\%200pioid\%20Manufacturers\%20 and\%20Third\%20Party\%20Advocacy\%20Groups.pdf

13. Crowe K. Following the money between patient groups and Big Pharma. CBC News. 2018 Feb 17 [cited 2020 Feb 24]. Available from: https://www.cbc.ca/news/health/second-opinion-patient-advocacypharmaceutical-industry-funding-drug-prices-1.4539271

14. Grant K. How a little-known agency reveals the web of influence between patient advocates and Big Pharma. Globe and Mail. 2018 Dec 13[cited 2020 Feb 27]. Available from: https://www.theglobeandmail. com/canada/investigations/article-how-a-little-known-agencyreveals-the-web-of-influence-between-patient/

15. Lexchin J. Association between commercial funding of Canadian patient groups and their views about funding of medicines: an observational study. PLOS One. 2019 Feb 15 [cited 2020 Feb 27]. doi. org/10.1371/journal.pone.0212399. Available from: https://journals. plos.org/plosone/article?id=10.1371/journal.pone.0212399

16. Mandeville KL, Barker R, Packham A, Sowerby C, Yarrow K, Patrick H. Financial interests of patient organisations contributing to technology assessment at England's National Institute for Health and Care Excellence: policy review. BMJ. 2019 Jan 16;364:k5300. doi: 10.1136/ bmj.k5300. Available from: https://www.bmj.com/content/364/bmj. k5300

17. Fabbri A, Swandari S, Lau E, Vitry A, Mintzes B. Pharmaceutical industry funding of consumer groups in Australia: a crosssectional analysis. Int J Health Serv. 2019 Jan 15;49(2): 273-93. doi. org/10.1177/0020731418823376.

18. Breast Cancer Action Quebec. Policy on corporate contributions, 2001 Mar 15[cited 2020 Feb 27]. Available from: http://www.acsqc.ca/policy

19. Lexchin J. Doctors in denial: why big pharma and the Canadian medical profession are too close for comfort. Toronto: Lorimer; 2017.344 pp.

20. Springer RA. Pharmaceutical industry influence: doctors' persistent illusion of unique invulnerability [Book review of Doctors in denial]. Indian J Med Ethics. 2019 Mar 5 [cited 2020 Feb 26]; 4(2). doi. org/10.20529/IJME.2019.008 Available from: https://ijme.in/articles/ pharmaceutical-industry-influence-doctors-persistent-illusion-ofunique-invulnerability/?galley=html

21. Marks $\mathrm{JH}$. The perils of partnership: industry influence, institutional integrity, and public health. New York: Oxford; 2019.

22. Banta D. Some conclusions from my life in health technology assessment. [Perspective] Int J Technol Assess Health Care. 2018; 34(2):131-3.

23. Forest, P-G, Martin D. Fit for purpose: findings and recommendations of the external review of the pan-Canadian health organizations (Summary Report). Ottawa: Government of Canada, 2018. Available from: https:// www.canada.ca/en/health-canada/services/health-care-system/ reports-publications/health-care-system/findings-recommendationsexternal-review-pan-canadian-health-organization.html

24. Krimsky S. Science in the private interest: Has the lure of profits corrupted biomedical research? New York: Rowman and Littlefield; 2004.

25. Relman A. Defending professional independence: ACCME's proposed new guidelines for commercial support of CME. JAMA. 2003;289(18):2418-2420. doi: 10.1001/jama.289.182418

26. Lexchin J, O'Donovan O. Prohibiting or 'managing' conflict of interest? A review of policies and procedures in three European drug regulation 
agencies. Soc Sci Med. 2010 Mar;70(5): 643-7. doi.org/10.1016/j. socscimed.2009.09.002.

27. Blackwell, T. The selling of OxyContin. National Post. 2011 Nov 12 [cited 2020 Feb 26]. Available from: https://nationalpost.com/news/canada/ the-selling-of-oxycontin

28. Crowe K. Opioid conflict-of-interest controversy reveals extent of big pharma's ties to doctors. CBC. 2017 May 19 [cited 2020 Feb 26]. Available from: https://www.cbc.ca/news/health/opioid-painphilpott-mcmaster-university-purdue-pharma-drug-industryconflict-1.4121956

29. Wong-Rieger D. Patient participation in HTA: evidence of real change? In Facey KM, Hanson HP, Single ANV, editors. Patient involvement in health technology assessment. Singapore: Springer Nature; 2017:373-80.

30. White MA. brief history of heckling. Guardian. 2006 Apr 28[cited 2020 Feb 26]. Available from: https://www.theguardian.com/politics/2006/ apr/28/past.labour.

31. Lehoux P, Blume S. Technology assessment and the sociopolitics of health technologies. J Health Polit Policy Law. 2000 Dec;25(6):10831120. doi.org/10.1215/03616878-25-61083

32. Abramson J. What will the Cochrane brand stand for? [Book review of Death of a whistleblower and Cochrane's moral collapse]. Indian J Med Ethics. 2019 Jul-Sep [cited 2020 Feb 26]; 4(3): 245-7. doi.10.20529/ IJME.2019.032 Available from: https://ijme.in/articles/what-will-thecochrane-brand-stand-for/

33. Pellerin R. Conspiracy of hope: The truth about breast cancer screening Fredericton, NB: Goose Lane Editions; 2018.

34. Wright CJ. Breast cancer screening: a different look at the evidence. Surgery. 1986. 100:594-7.

35. Banta DH, Thacker SB. Electronic fetal monitoring: lessons from a formative case of health technology assessment. Int J Technol Assess Health Care. 2002; 18(4):762-70. doi.10.1017/S0266462302000570
36. Lenzer J. Lay campaigners for prostate screening are funded by industry. BMJ. 2003 Mar 29; 326:680. doi: 10.1136/bmj.326.7391.680

37. Pharmaphorum. Patient opinion leaders: the new KOLs for pharma? UK: Pharmaphorum Premium Media. 2014.

38. Moynihan R. Key opinion leaders: independent experts or drug representatives in disguise? BMJ. 2008 Jun 21; 336(7658):1402-3. doi: 10.1136/bmj.39575.675787.651

39. Carlat D. Dr. Drug Rep. New York Times Magazine. 2007 Nov 25[cited 2020 Feb 26]. Available from: https://www.nytimes.com/2007/11/25/ magazine/25memoir-t.html

40. Boyer A.The undying:What cancer takes away. New Yorker. 2019 Apr 18 [cited 2020 Feb 26].; 28-33.

41. Lenzer J. The danger within us: America's untested, unregulated medical device industry and one man's battle to survive it. New York: Little Brown; 2017.

42. Crowe K. Canadian families stunned by 3,000\% increase in price of lifesaving drug. CBC News. 2018 Mar 10 [cited 2020 Feb 26]. Available from: https://www.cbc.ca/news/health/second-opinion-procysbi-cystagonmarch10-1.4570152

43. Canadian Agency for Drugs and Technologies in Health. Code of Conduct for CADTH Events. Ottawa: CADTH.org; 2019 Jan [cited 2020 Feb 26]. Available from: https://symposium.cadth.ca/code-of-conductfor-cadth-events/

44. Canadian Agency for Drugs and Technologies in Health. CADTH Patient Community Liaison Forum -- Active 2013-2018. Ottawa: CADTH.org; 2020 [cited 2020 Feb 26]. Available from: https://cadth.ca/cadthpatient-community-liaison-forum-active-2013-2018

45. Canadian Agency for Drugs and Technologies in Health. Advisory Bodies: Patient and community advisory committee. Members. Ottawa: CADTH.org; 2019 Jan [cited 2020 Feb 26]. Available from: https://cadth $\mathrm{ca} /$ patient-and-community-advisory-committee

\section{Pregnancy and severe mental illness: Confounding ethical doctrines}

\section{JITENDER ANEJA, SONAM ARORA}

\section{Abstract}

Pregnancy brings joy and excitement to some women, but great distress to those who suffer from severe mental illnesses like schizophrenia. Women with severe mental illnesses (SMIs) may have difficulty planning a pregnancy and deciding whether to continue to viability, and thence to term. Dilemmas also surround pharmacotherapy for this population, as (non)treatment is associated with its own challenges. The psychiatrist may have to make challenging decisions based on the principles of autonomy beneficence, and relational ethics. Furthermore, there are ethical controversies inherent to the underlying pathologies, their nontreatment, and the various psychosocial factors that could impact parenting in such mothers. In addition, limited or ineffective use

Authors: Jitender Aneja (anejajitender@gmail.com; corresponding author), Associate Professor, Department of Psychiatry, All India Institute of Medical Sciences, Jodhpur- Romana, Punjab 151001, INDIA; Sonam Arora (asonam2720@gmail.com), Consultant Pathologist, Metropolis Healthcare Limited, Sector-11 D, Chandigarh, 160011 INDIA

To cite: Aneja J, Arora S. Pregnancy and severe mental illness: Confounding ethical doctrines. Indian J Med Ethics. 2020 Apr-Jun;5(2) NS: 133-9. DOI: 10.20529/IJME.2020.037.

Published online on April 16, 2020.

Manuscript Editor: Rakhi Ghoshal

Peer Reviewer: Alok Sarin

(c) Indian Journal of Medical Ethics 2020 of family planning, mental health services, and contraception often act as forerunners of these problems. Considering the sparse literature on this topic and the perplexing legal responsibilities pertaining to the recently implemented Mental Health Care Act, 2017, we have attempted to highlight the various ethical dilemmas that confront a psychiatrist while managing a patient from this group.

Keywords: pregnancy, perinatal, severe mental illness, schizophrenia, psychosis, ethics

\section{Introduction}

Ethical issues and psychiatric practice are the two sides of a seesaw, and are often difficult to balance, with pregnancy adding further complications to this intricate equilibrium. The well-being of a pregnant woman with a serious mental illness (SMI) is influenced by her underlying mental pathology, a plethora of pregnancy-associated psychiatric disorders, and various psychosocial etiological factors. In addition, her unborn child may be affected by the parents' genetic predispositions, pharmaco-treatment, and disrupted parental relationships. In these situations, while catering to the woman and her foetus, the psychiatrist needs to consider the severity of the mental illness, respect her autonomy, and take into account ethical issues. Advances in treatment and the improved sensitisation 